\title{
Optimization of the Extraction Technology of Chlorogenic Acid in Honeysuckle by Response Surface Method
}

\author{
Tingting Cui ${ }^{*}$, Chao Wang2, Changsong Shan 1 , Peng Wu ${ }^{1^{*}}$ \\ ${ }^{1}$ College of Food Science and Technology, Shandong Agriculture University, Taian, China \\ ${ }^{2}$ College of Horticulture Science and Engineering, Shandong Agricultural University, Taian, China

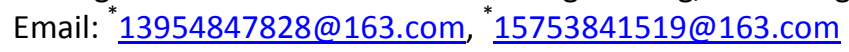

Received 3 June 2014; revised 13 July 2014; accepted 23 August 2014

Copyright (C) 2014 by authors and OALib.

This work is licensed under the Creative Commons Attribution International License (CC BY).

http://creativecommons.org/licenses/by/4.0/

c. (i) Open Access

\section{Abstract}

The ultrasound-assisted extraction of chlorogenic acid from honeysuckle was modeled using response surface methodology. A three-level-three-factor Box-Behnken design was employed to optimize three extraction variables, including extraction temperature $\left(\mathrm{X}_{1}\right)$, ethanol concentration $\left(X_{2}\right)$, and soak time $\left(X_{3}\right)$, for the achievement of high extraction yield of the chlorogenic acid. The optimized conditions are extract temperature of $80^{\circ} \mathrm{C}$, ethanol concentration of $70.37 \%$, soak time of $9.35 \mathrm{~h}$. Under this optimized conditions, the experimental yield of chlorogenic acid is $1.918 \%$, which is well matched with the predicted yield of $1.929 \%$.

\section{Keywords}

Design-Expert Software, Lonicera Japonica, Chlorogenic Acid, Extraction Technology Optimization

Subject Areas: Analytical Chemistry, Food Science \& Technology

\section{Introduction}

Honeysuckle, the flower-bud or flower of Lonicera japonica Thund which also called double flower, tastes fresh and sweet. It is widely used for the treatment of tumors, bacterial dysentery, cold, pain, sores, carbuncles, furuncles, swelling and fever disease caused by influenza virus [1]. Studies have been found that honeysuckle contains many kinds of antioxidant and anti-tumor compounds such as chlorogenic acid, flavonoid, triterpenoid saponins, polysaccharides and volatile oil [2]. Chlorogenic acid, as the major bioactive constituent of honeysuckle, has been shown the function of anti-bacterial anti-inflammatory, liver-protection, hypolipidemic effect, detoxi-

*Corresponding authors.

How to cite this paper: Cui, T.T., Wang, C., Shan, C.S. and Wu, P. (2014) Optimization of the Extraction Technology of Chlorogenic Acid in Honeysuckle by Response Surface Method. Open Access Library Journal, 1: e941.

http://dx.doi.org/10.4236/oalib.1100941 
cation and anti-mutagenic and it is beneficial to the immune system pharmacological activities [3]. So it is important to study the effective extraction of chlorogenic acid from honeysuckle.

Design-Expert, as the most comprehensive, affinity design software, has functions such as statistical analysis of test data; establishing the mathematical model, fit curve equation, prediction and optimization of the test results. Besides, two-dimensional contour map and 3D graphics also can be drawn by it [4]. Presently, the design software has been widely used in all kinds of experimental design and analysis. Wu Jiahui studied enzyme-assisted extraction of lentinan by using this software [5]; the corn fertilizer production mushroom mycelium was studied by Lee S. through response surface method [6].

As a new extraction technology, it is widely used in the extraction of natural products, heat sensitive material, particularly. In addition, ultrasonic extraction can protect active material; short extraction time, and improve extraction efficiency. Assisted by the response surface design of ultrasonic extraction method not only improves the chlorogenic acid yield but also simplifies the experiment process [7] [8].

In order to seek the best extraction method of chlorogenic acid in Lonicera japonica to provide theoretical reference, the single factor and center combining with experiment and the software of Box-Behnken center was adopted in this research.

\section{Experimental}

\subsection{Materials and Chemicals}

Purchased from the National Institute for the Control of Pharmaceutical and Biological Products (Beijing, China), Chlorogenic acid ( $\mathrm{J} \& \mathrm{~K}$, purity is $98 \%$ ) was dissolved in $95 \%$ ethanol and stored at $-20^{\circ} \mathrm{C}$. Other reagents were analytical grade and purchased from Tianjin Chemical Reagent Factory (Tianjin, China). Distilled water was used throughout the whole experiment.

Honeysuckle used in this study was harvested from Xintai Tai'an (Tai'an China). Dried honeysuckle crushed in Micro Plant Grinding Machine and then sieved through a wire mesh to remove the midrib materials. Representative $1.000 \mathrm{~g}$ samples were weighed on an electronic analytical balance TW 223L from the Shimadzu Japan Instruments Co., Ltd.

\subsection{Apparatus and Equipments}

Sonication of samples was done using an Ultrasonic Generator 2510E-DTH (245 watts, $42 \mathrm{kHz}$ ) purchased from Branson Ultrasonic Corporation in USA. An automatically adjustable HH-4 Constant Temperature Water Bath from Guohua Electric Appliance Co., Ltd. was used to control the extraction temperature. A laboratory thermometer was used to monitor the effectiveness of the temperature control. The crude extracts were centrifuged in a X1R High Speed Multifuge from Beijing Aoheng Technology Co., Ltd. and then filtered. The filtered extracts were analyzed by an UV 2430 spectrophotometer from Shimadzu Japan Instruments Co., Ltd.

\subsection{Ultrasonic Extraction}

One gram of dried Honeysuckle powder was weighted accurately to a flask, and then $30 \mathrm{~mL}$ ethanol was added to the Erlenmeyer flask which was sealed with silver paper. The powder was extracted in an ultrasonic generator for different extraction time and temperature at various ethanol concentrations. After ultrasonic treatment, the extracted slurry was centrifuged at 3000 rpm for 20 min to collect the supernatant and then transfer to flask volumetric.

\subsection{Determination of Chlorogenic Acid Yield}

The total chlorogenic acid content in the supernatant was determined using Chlorogenic acid-standard curve method with a slight modification. And then the percentage of chlorogenic acid yield is calculated as follows:

$$
Y=\frac{\frac{A-0.0081}{52.533} \times V \times N \times 10^{-3}}{M} \times 100 \%
$$

In the above formula: $Y$ is percentage chlorogenic acid yield (\%), $A$ is absorbance value of sample solution, $V$ is volume (mL) of extract supernatant, $N$ is dilution ratio, and $M$ is the quantity of honeysuckle (g). 


\subsection{Experimental Design}

A three-level-three-factor, Box-Behnken Design (BBD) was employed to determine the best combination of extraction variables for the chlorogenic acid compounds based on the results of preliminary single-factor-test [9] [10]. Extraction temperature $\left(X_{1}\right)$, ethanol concentration $\left(X_{2}\right)$, and soak time of raw material $\left(X_{3}\right)$ were the independent variables, and their coded and uncoded levels were presented in Table 1. Extraction yield (Y) taken as the response for the design experiment was given in Table 2.

\subsection{Statistical Analysis}

Each test was repeated three times, and calculated the averaged. SPSS software version 16.0 and Sigma Plot 10.0 was used to evaluate the analysis of variance (ANOVA) and draw the figures, respectively. And then the trend charts, responds surface and contour plots of various factors on the chlorogenic acid yield were draw.

\section{Results}

\subsection{Optimization of Maximum Absorption Wavelength for Chlorogenic Acid}

According to the method of 2.4, the maximum absorption wavelength of chlorogenic acid was $324.3 \mathrm{~nm}$ and the standard curve equation was $y=52.533 x+0.0081, R^{2}=0.9997$. As can be seen from Figure 1 , the results showed that the chlorogenic acid concentration within $0-0.02 \mathrm{mg} / \mathrm{mL}$ meet good linear range relationship.

\subsection{Result of Single-Factor-Test}

\subsubsection{Effect of Ethanol Concentration on Extraction Yield of Chlorogenic Acid}

Extraction process was carried out at different ethanol concentration of $50 \%, 60 \%, 70 \%, 80 \%$ and $90 \%$, while other parameters were as following: extraction time $50 \mathrm{~min}$, soak time $6 \mathrm{~h}$ and extraction temperature $70^{\circ} \mathrm{C}$. The

Table 1. Independent variables and their levels for Box-Behnken design.

\begin{tabular}{cccc}
\hline Independent variables & \multicolumn{3}{c}{ Levels } \\
\cline { 2 - 4 } & -1 & 0 & 1 \\
\hline Extraction temperature $\left(\mathrm{X}_{1}\right)\left({ }^{\circ} \mathrm{C}\right)$ & 60 & 70 & 80 \\
Ethanol concentration $\left(\mathrm{X}_{2}\right)(\%)$ & 60 & 70 & 80 \\
Soak time $\left(\mathrm{X}_{3}\right)(\mathrm{h})$ & 6 & 9 & 12 \\
\hline
\end{tabular}

Table 2. Effect of different response surface design of extraction rate of chlorogenic acid.

\begin{tabular}{|c|c|c|c|c|}
\hline Run & $\begin{array}{c}\mathrm{X}_{1} \\
\text { Extraction temperature }\left({ }^{\circ} \mathrm{C}\right)\end{array}$ & $\begin{array}{c}\mathrm{X}_{2} \\
\text { Ethanol concentration (\%) }\end{array}$ & $\begin{array}{c}\mathrm{X}_{3} \\
\text { Soak time (h) }\end{array}$ & $\begin{array}{c}\mathrm{Y} \\
\text { Extraction yield (\%) }\end{array}$ \\
\hline 1 & 70 & 60 & 6 & 1.634 \\
\hline 2 & 60 & 60 & 9 & 1.594 \\
\hline 3 & 60 & 80 & 9 & 1.446 \\
\hline 4 & 70 & 60 & 12 & 1.574 \\
\hline 5 & 70 & 70 & 9 & 1.893 \\
\hline 6 & 70 & 80 & 6 & 1.494 \\
\hline 7 & 70 & 70 & 9 & 1.910 \\
\hline 8 & 80 & 80 & 9 & 1.767 \\
\hline 9 & 60 & 70 & 6 & 1.533 \\
\hline 10 & 60 & 70 & 12 & 1.475 \\
\hline 11 & 80 & 70 & 12 & 1.806 \\
\hline 12 & 80 & 60 & 9 & 1.733 \\
\hline 13 & 70 & 70 & 9 & 1.904 \\
\hline 14 & 80 & 70 & 6 & 1.713 \\
\hline 15 & 70 & 80 & 12 & 1.534 \\
\hline
\end{tabular}




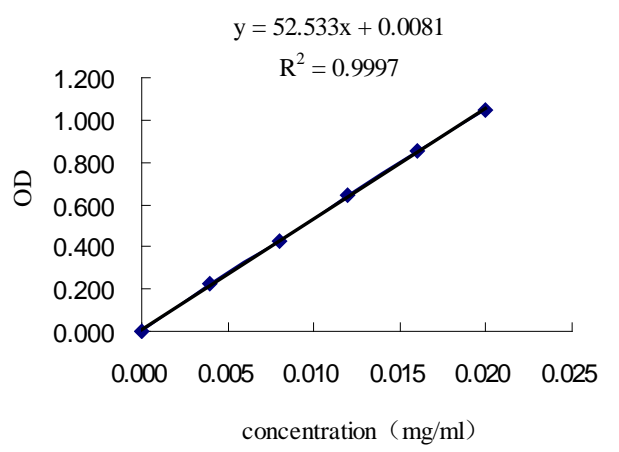

Figure 1. The curve of standard chlorogenic acid sample.

effect of ethanol concentration on extraction yield of chlorogenic acid is shown in Figure 2(a). In the initial stage, along with the ethanol concentration increased from $50 \%$ to $70 \%$, the extraction yield of chlorogenic acid increased rapidly; while ethanol concentration greater than $70 \%$ chlorogenic acid extraction yield was showing slow decreasing trend, and peak at 70\% ethanol concentration. This is because the increase of ethanol concentration leads to enhanced mass transfer dynamics, solvents and honeysuckle getting full access, and then the contents of chlorogenic acid dissolved increased [11]. When the ethanol concentration reached a certain level, some of chlorogenic acid was difficult to be dissolved by high concentration of ethanol, and also lead to the increase of the alcohol-soluble impurity content, resulting in a loss of chlorogenic acid content [12]. Moreover, the greater of ethanol concentration, the more difficult to refine chlorogenic acid and it will cause wasted and the cost of production increased. Therefore, the ethanol concentration of $70 \%$ is good for the chlorogenic acid extraction.

\subsubsection{Effect of Extraction Temperature on Extraction Yield of Chlorogenic Acid}

Extraction process was carried out using extraction temperature from 40 to $80^{\circ} \mathrm{C}$, while other parameters were as following: Ethanol concentration 50\% (v/v), soak time $6 \mathrm{~h}$ and extraction time $30 \mathrm{~min}$. As shown in Figure 2(b), extraction temperature has obvious effects on yield of chlorogenic acid. When extraction temperature increased, the extraction yield increased rapidly and reached a maximum at $70^{\circ} \mathrm{C}$, when extraction temperature went above $70^{\circ} \mathrm{C}$, the extraction yield started to decrease. At initially, extraction yield increasing with the rising of temperature may be that elevated temperature accelerated the chlorogenic acid chemical bond rupture and speeded molecular motion, so that a large number of chlorogenic acid in cell dissolution into the solution [13]. when heating temperature greater than $70^{\circ} \mathrm{C}$, high temperature caused the destruction of chlorogenic acid structure, accelerated the degradation reaction, and lost chlorogenic acid activity, and then Chlorogenic acid content is rapidly reduced [14]. Therefore, $70^{\circ} \mathrm{C}$ is favorable for extracting the chlorogenic acid.

\subsubsection{Effect of Extraction Time on Extraction Yield of Chlorogenic Acid}

Extraction process was carried out using extraction time from 20 to $60 \mathrm{~min}$, while other parameters were as following: ethanol concentration $50 \%(\mathrm{v} / \mathrm{v})$, soak time $6 \mathrm{~h}$ and extraction temperature $70^{\circ} \mathrm{C}$. The experiment results showed that $50 \mathrm{~min}$ is the optimum extraction time of the chlorogenic acid, as shown in Figure 2(c). When extraction time increased, the cell walls of honeysuckle got fully fall apart and chlorogenic acid got into material liquid diffusion so that the extraction yield is relatively rapid [15]. During long extraction time, honeysuckle local overheating was prone to cause thermal decomposition of chlorogenic acid, because of the unstable chemical bonds of chlorogenic acid molecular, such as eater bond, unsaturated bond and polyphenol [16]. And then the honeysuckle content was decreased. Therefore, $50 \mathrm{~min}$ is favorable for extracting the chlorogenic acid.

\subsubsection{Effect of Soak Time on Extraction Yield of Chlorogenic Acid}

Extraction process was carried out at different soak time of $3 \mathrm{~h}, 6 \mathrm{~h}, 9 \mathrm{~h}, 12 \mathrm{~h}$, and $15 \mathrm{~h}$, while other parameters were as following: ethanol concentration $50 \%(\mathrm{v} / \mathrm{v})$, extraction time $50 \mathrm{~min}$ and extraction temperature $70^{\circ} \mathrm{C}$. The experiment results were shown in Figure 2(d). When soak time increased, the extraction yield was relatively rapid and reached a maximum at $9 \mathrm{~h}$, and then decreased as the extraction proceeds. This is because the chlorogenic acid can soluble in organic solvents, such ethanol and so on [17]. Increasing the immersion time 

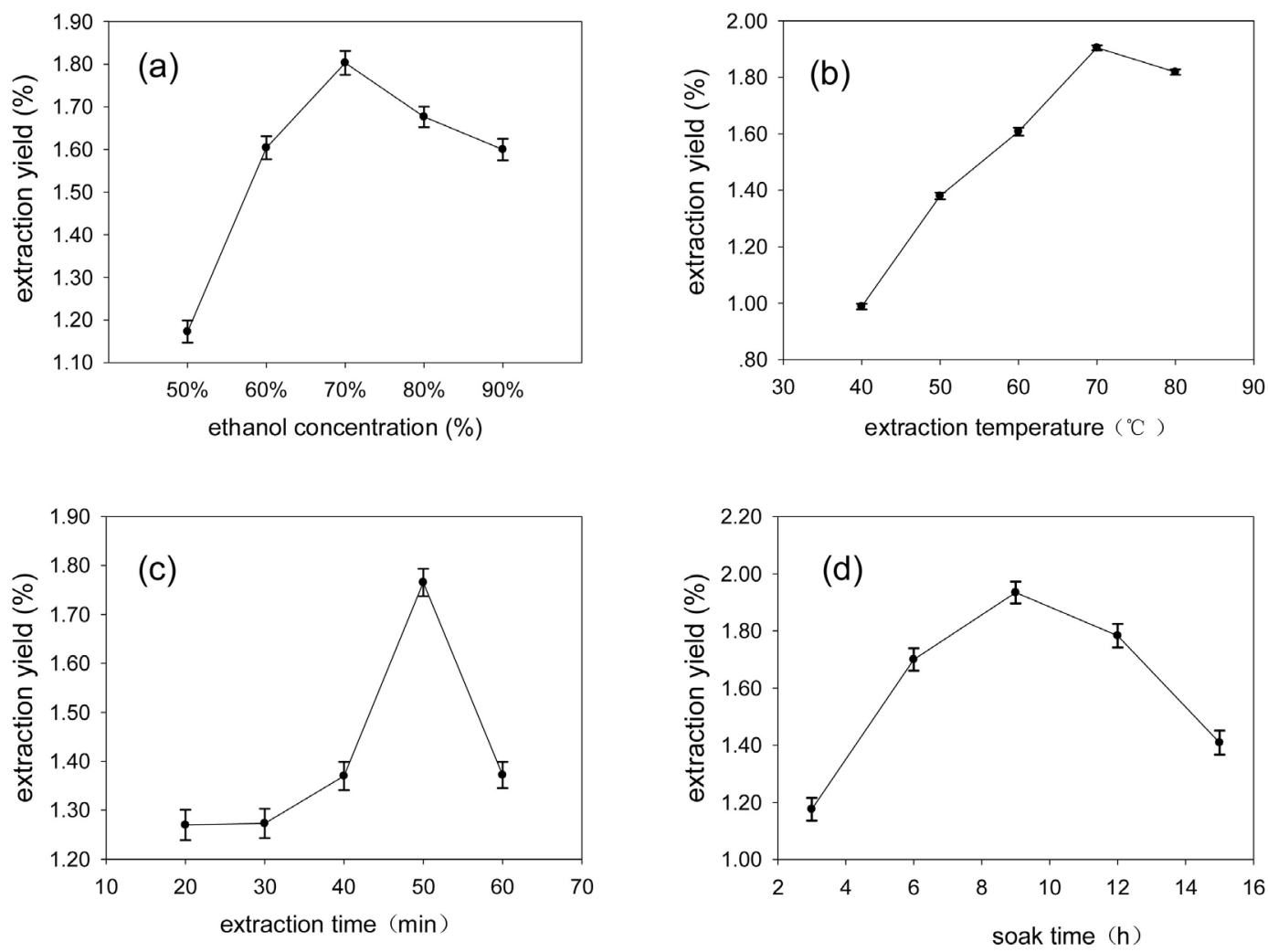

Figure 2. Effect of different extraction variables on extraction yield.

made full chlorogenic acid dissolution, so chlorogenic acid content increased. However, once again increasing the immersion time increased the lead to impurities in solution, and the leaching of impurities adsorbed portion of chlorogenic acid, resulting in loss of yield lower [18]. Therefore, $9 \mathrm{~h}$ is favorable for extracting the chlorogenic acid.

\subsection{Optimization of Extraction Parameters for Chlorogenic Acid}

Table 2 showed the process variables and experimental data of 15 runs containing 3 replicates at center point. By applying multiple regression analysis on the experimental data, the model for the response variable could be expressed by the following quadratic polynomial equation in the form of coded values:

$$
\begin{aligned}
y & =-9.79065+0.10483 X_{1}+0.19496 X_{2}+0.20017 X_{3}+0.000456 X_{1} X_{2} \\
& +0.001263 X_{1} X_{3}+0.000834 X_{2} X_{3}-0.000971 X_{1}^{2}-0.001700 X_{2}^{2}-0.019246 X_{3}^{2}
\end{aligned}
$$

Analysis of variance (ANOVA) for the model was shown in Table 3. The determination coefficient $\left(\mathrm{R}^{2}=\right.$ 0.9963) indicated that only $0.37 \%$ of the total variations were not explained by the model. For a good statistical model, the adjusted determination coefficient $\left(\mathrm{R}_{\text {adj }}\right.$ ) should be close to determination coefficient $\left(\mathrm{R}^{2}\right)$. As shown in Table 3, $R_{\text {adj }}^{2}(0.9896)$ was close to $R^{2}$. Moreover, $R_{\text {pred }}^{2}(0.9462)$ was in reasonable agreement with $R_{\text {adj }}^{2}$ and the results confirmed that the model was highly significant. At the same time, a relatively low value of coefficient of variation (CV) (0.99) indicates a better precision and reliability of the experimental values. Therefore, the model is adequate for prediction in the range of experimental variables.

As can be seen from Table 4, the lack of fittest determines whether the selected model is adequate to explain the experimental data, or whether another model should be reselected. The significance of each coefficient measured using p-value and F-value is listed in Table 4. Smaller p-value and greater F-value mean that the corresponding variables would be more significant. The p-value of the model is less than 0.0001 , which indicates that the model is significant and can be used to optimize the extraction variables. The one independent variables $\left(\mathrm{X}_{1}\right)$, interaction terms $\left(\mathrm{X}_{1} \mathrm{X}_{2}, \mathrm{X}_{1} \mathrm{X}_{3}\right)$ and three quadratic terms $\left(\mathrm{X}_{1}{ }^{2}, \mathrm{X}_{2}{ }^{2}\right.$ and $\left.\mathrm{X}_{3}{ }^{2}\right)$ significantly $(\mathrm{P}<0.01)$ affect 
Table 3. The correlation analysis of model.

\begin{tabular}{cl}
\hline $\mathrm{R}^{2}$ & 0.9963 \\
\hline $\mathrm{R}_{\text {adj }}^{2}$ & 0.9896 \\
$\mathrm{R}_{\text {pred }}$ & 0.9462 \\
C.V. \% & 0.9900 \\
\hline
\end{tabular}

Table 4. Significance test of regression coefficients.

\begin{tabular}{cccccc}
\hline Source & Sum of squares & Degree of freedom & Mean square & F-value & P-value $(\operatorname{Pr}>\mathrm{F})$ \\
\hline Model & 0.3700000 & 9 & 0.04100000 & 149.66 & $<0.0001$ \\
$\mathrm{X}_{1}$ & 0.1200000 & 1 & 0.12000000 & 433.31 & $<0.0001$ \\
$\mathrm{X}_{2}$ & 0.0110000 & 1 & 0.01100000 & 39.49 & 0.0015 \\
$\mathrm{X}_{3}$ & 0.0000251 & 1 & 0.00002500 & 0.092 & 0.7738 \\
$\mathrm{X}_{1} \mathrm{X}_{2}$ & 0.0083410 & 1 & 0.00834100 & 30.59 & 0.0026 \\
$\mathrm{X}_{1} \mathrm{X}_{3}$ & 0.0057500 & 1 & 0.00575000 & 21.09 & 0.0059 \\
$\mathrm{X}_{2} \mathrm{X}_{3}$ & 0.0025050 & 1 & 0.00250500 & 9.18 & 0.0291 \\
$\mathrm{X}_{1}{ }^{2}$ & 0.0350000 & 1 & 0.03500000 & 127.82 & $<0.0001$ \\
$\mathrm{X}_{2}{ }^{2}$ & 0.1100000 & 1 & 0.11000000 & 391.67 & $<0.0001$ \\
$\mathrm{X}_{3}{ }^{2}$ & 0.1100000 & 1 & 0.11000000 & 406.29 & $<0.0001$ \\
residual & 0.0013630 & 5 & 0.00027270 & & 0.1549 \\
Lack of fit & 0.0012190 & 3 & 0.00040620 & 5.61 & \\
Pure error & 0.0001447 & 2 & 0.00007235 & & \\
Total error & 0.3700000 & 14 & & & \\
\hline
\end{tabular}

the extraction yield within a $99 \%$ confidence interval. Meanwhile, extraction time $\left(\mathrm{X}_{1}\right)$ is the most significant factor affecting the extraction yield.

$3 \mathrm{D}$ response surface and 2D contour plots are the graphical representations of regression equation and they are very useful to judge the relationship between independent and dependent variables. Different shapes of the contour plots indicate whether the mutual interactions between the variables are significant or not. Circular contour plot means the interactions between the corresponding variables are negligible, while elliptical contour suggests the interactions between the corresponding variables are significant. The three-dimensional representation of the response surfaces and two-dimensional contours generated by the model are shown in Figures 3-5. In these three variables, when two variables are depicted in three-dimensional surface plots, the third variable is fixed at zero level. It is found in Figures 3-5 that all the three response surfaces are convex in shape, which indicates that the ranges of variables were chosen properly.

As shown in Figure 3, extraction yield increased rapidly when extraction temperature $\left(\mathrm{X}_{1}\right)$ and ethanol concentration $\left(\mathrm{X}_{2}\right)$ increased in the range of $60^{\circ} \mathrm{C}-75^{\circ} \mathrm{C}$ and $65 \%-75 \%$, respectively; but beyond $75^{\circ} \mathrm{C}$ and $75 \%$, extraction yield decreased slightly. The results demonstrated that the effect of extraction temperature $\left(\mathrm{X}_{1}\right)$ and ethanol concentration $\left(\mathrm{X}_{2}\right)$ on extraction yield was significant and the results were in good agreement with the results in Table 4. Moreover, the elliptical contour plots in Figure 3 mean that there was a significant interaction between the two variables, which also agrees with the results in Table 4. As shown in Figure 4, both extraction temperature $\left(\mathrm{X}_{1}\right)$ and soak time $\left(\mathrm{X}_{3}\right)$ have quadratic effect on extraction yield. Extraction yield increases at first and then decreased quickly with increasing of the two parameters, and a maximum extraction yield is achieved when extraction temperature $\left(\mathrm{X}_{1}\right)$ and soak time $\left(\mathrm{X}_{3}\right)$ are $70^{\circ} \mathrm{C}$ and $9 \mathrm{~h}$, respectively. It can be seen that the mutual interactions between extraction temperature $\left(\mathrm{X}_{1}\right)$ and soak time $\left(\mathrm{X}_{3}\right)$ was significant due to the elliptical contour plots shown in Figure 4, which was also confirmed by the results in Table 4. It is obvious in Figure 5 that extraction yield increases slowly with the increasing of ethanol concentration $\left(\mathrm{X}_{2}\right)$ and decreases slowly after $70 \%$; while extraction yield increases rapidly with the increasing of soak time $\left(\mathrm{X}_{3}\right)$ from 6 to $9 \mathrm{~h}$ and decreases rapidly after $9 \mathrm{~h}$. The results suggested that the interactions between the two variables were not significant, which was in agreement with the contour plots in Figure 5 and the results in Table 4. 

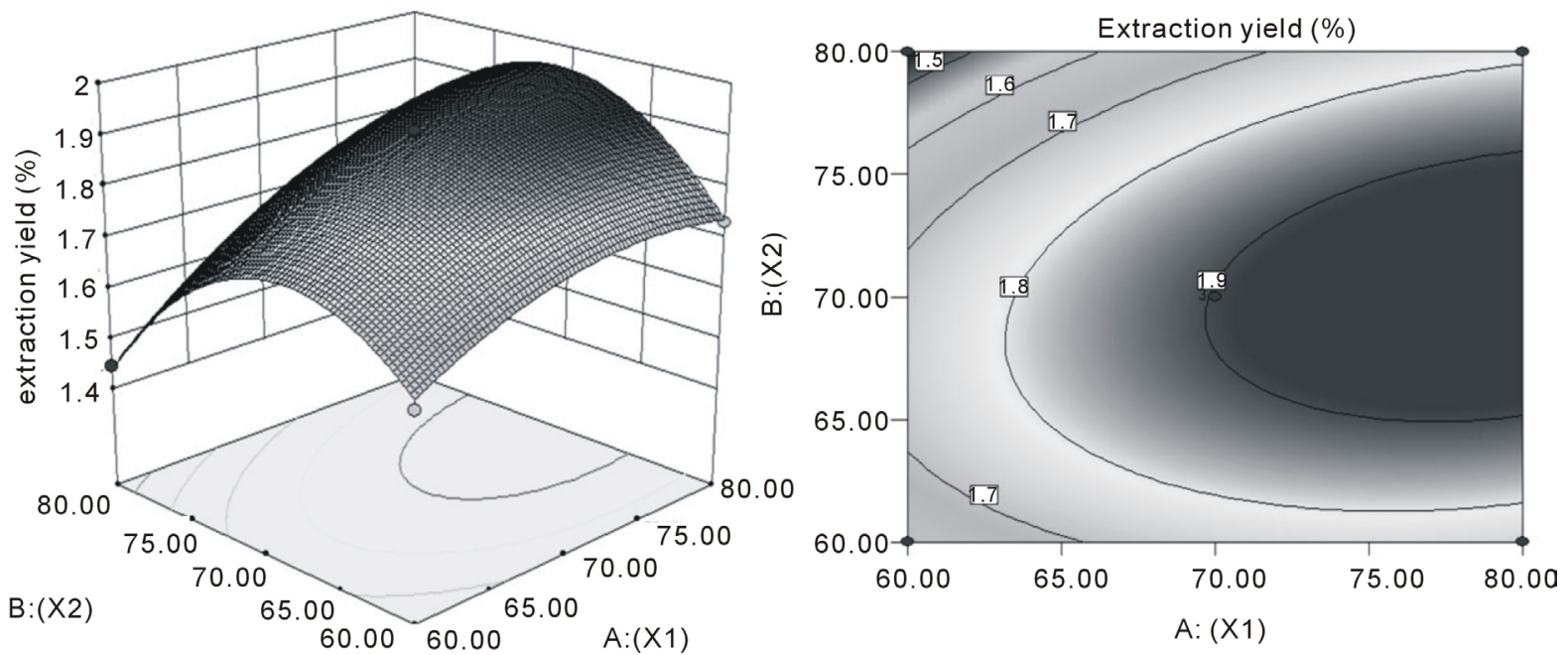

Figure 3. Response surface and contour plots showing effect of extraction temperature $\left(\mathrm{X}_{1}\right)$ and ethanol concentration $\left(\mathrm{X}_{2}\right)$.
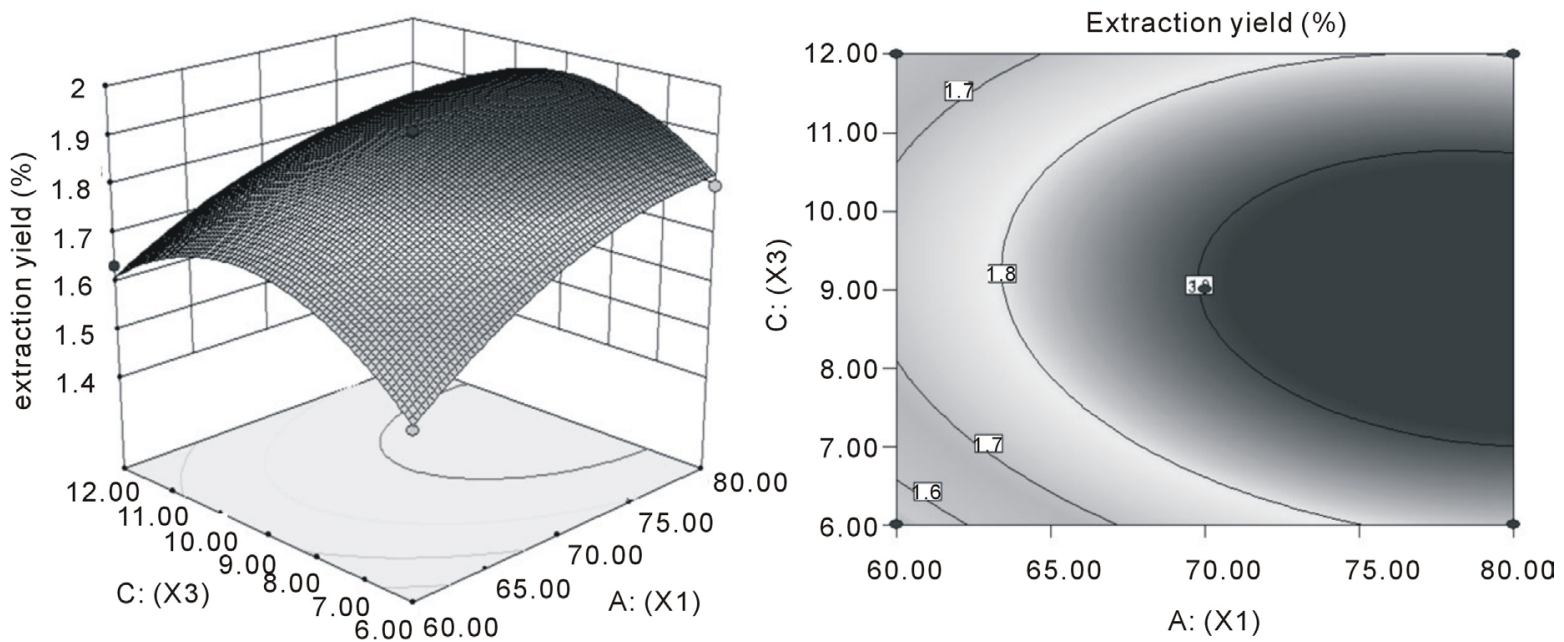

Figure 4. Response surface and contour plots showing effect of extraction temperature $\left(\mathrm{X}_{1}\right)$ and soak time $\left(\mathrm{X}_{3}\right)$.
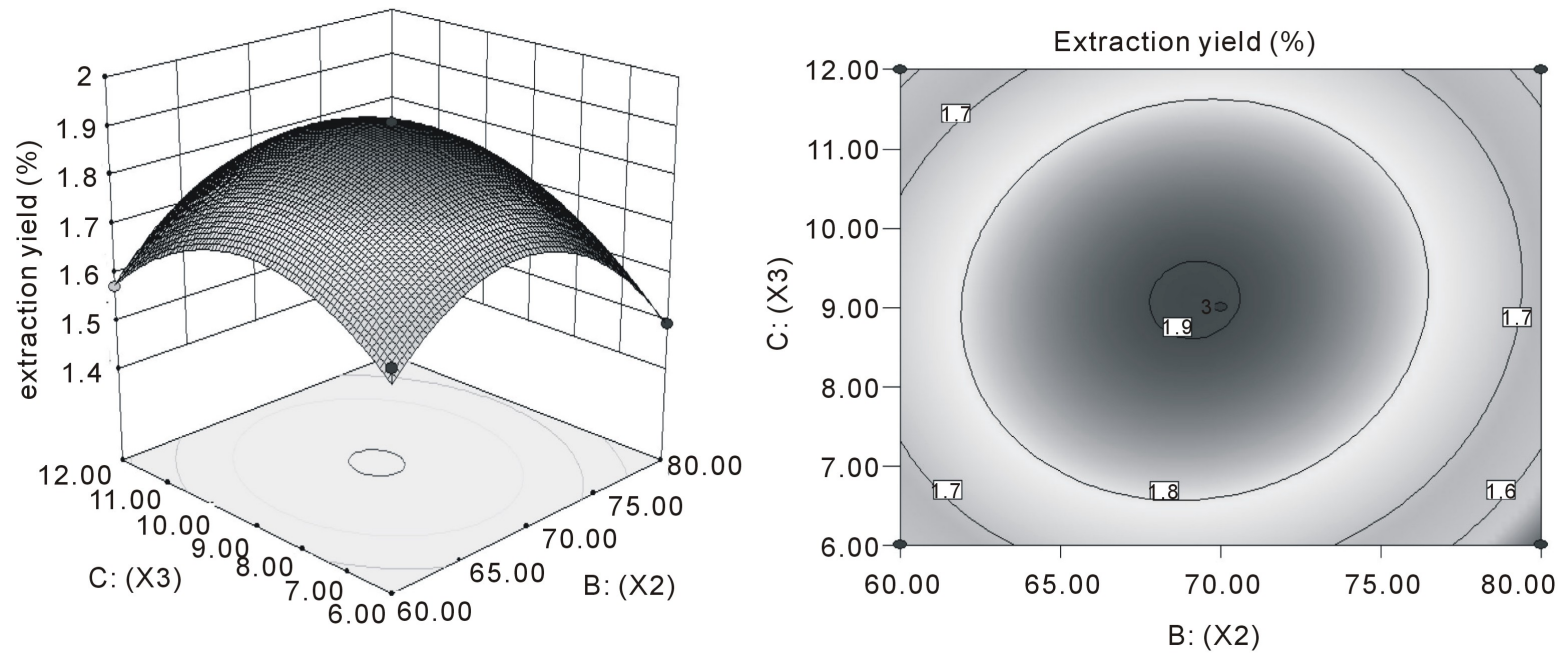

Figure 5. Response surface and contour plots showing effect of ethanol concentration $\left(\mathrm{X}_{2}\right)$ and soak time $\left(\mathrm{X}_{2}\right)$. 


\subsection{Verification of the Model}

The suitability of the model equation for predicting the optimum response values is tested using the selected optimum conditions. The optimum conditions are extraction temperature $\left(\mathrm{X}_{1}\right)$ of $80^{\circ} \mathrm{C}$, ethanol concentration $\left(\mathrm{X}_{2}\right)$ of $70.37 \%$, and soak time $\left(\mathrm{X}_{3}\right)$ of $9.35 \mathrm{~h}$, under which the predicted yield is $1.929 \%$. However, considering the operability in actual production, the optimum conditions are modified as following: extraction temperature $\left(\mathrm{X}_{1}\right)$ of $80^{\circ} \mathrm{C}$, ethanol concentration $\left(\mathrm{X}_{2}\right)$ of $70 \%$, and soak time $\left(\mathrm{X}_{3}\right)$ of $9 \mathrm{~h}$, under which the experimental yield is $1.911 \%(\mathrm{n}=3)$. The theoretical prediction error is $1.13 \%$, agreeing closely with the predicted yield. Consequently, adopting the response surface method to seek the best condition of extracting honeysuckle chlorogenic acid is feasible, and has practical significance.

\section{Conclusions and Discussion}

An ultrasonic-assisted extraction technology was performed for the extraction of chlorogenic acid from honeysuckle and optimized by RSM. Based on the single-factor-test, Box-Behnken design was used to evaluate and optimize the extraction variables (extraction temperature, ethanol concentration and soak time) for the extraction yield. The results showed that the variables (soak time and ethanol concentration) are significant and a high correlation of quadratic model obtained is satisfactory and accurate to predict the extraction yield, which was similarity to the reported [19] [20]. The optimized conditions are as follows: extraction temperature of $80^{\circ} \mathrm{C}$, ethanol concentration of $70 \%$, and soak time of $9 \mathrm{~h}$, under which the experimental yield is $1.911 \%(\mathrm{n}=3)$, which is agreed closely with the predicted yield of $1.929 \%$. Therefore, method for the extraction of chlorogenic acid plays an active guidance of theory.

Chlorogenic acid is one of the main active substances of Lonicera japonica. In order to increase extraction yield of Chlorogenic acid, this experiment test influence factors, such as soak time, which were rare reported. As shown in Figure 2(d), with the increase of soak time, chlorogenic acid yield increased; when the soak time is more than $9 \mathrm{~h}$, extraction yield was slow down. This is because the chlorogenic acid can dissolve in organic solvent. Before extraction, the chlorogenic acid fully dissolve out after a certain amount of time, and the extension of time not only lead to increased alcohol soluble impurities, but also the impurities can soak up some chlorogenic acid. Compared with the honeysuckle without soaking in related report, extraction yields in the experiments greatly increased [21]. Yuan Fei [22] optimized the ultrasonic extraction process of chlorogenic acid in Lonicera japonica. The ultrasonic extraction conditions were that the soak time of $12 \mathrm{~h}$ and then ultrasonic extraction of 2 times; the chlorogenic acid yield after decompression enrichment was $2.110 \%$, which higher $0.181 \%$ than this experiment. This may be related to the extraction conditions and other objective factors. So we should take various factors into accounts during the experiment, and strictly control test conditions. Extraction times, as the influence factors of yield, should be tested during experiment, to determine the change trends on the yield of chlorogenic acid.

Ultrasonic extraction not only can protect active substance from destruction, but also has many advantages, such as short extraction time, increase of extraction efficiency, low cost and easy operation and so on. Hence, ultrasonic extraction is widely used in natural products extraction, especially in the extraction of heat sensitive materials. Assisted by the response surface design of ultrasonic extraction method not only improves the chlorogenic acid yield, but also simplifies the experiment process. In recent years, the application of ultrasonic extraction technology is becoming more common in industrial extraction of chlorogenic acid in Lonicera japonica.

Combining response surface methodology and ultrasonic extraction not only improved the chlorogenic acid yield but also simplified the experiment process. In order to develop series honeysuckle functional health products and ensure the steady development of the honeysuckle industry, deep processing and system development of this Lonicera japonica will provide scientific theoretical basis for it.

\section{Funding}

Supported by youth science and technology innovation foundation of Shandong Agricultural University (No.20120604).

\section{References}

[1] Chinese Pharmacopoeia Commission (2010) Chinese Pharmacopoeia. China Medical Science Press, Beijing, 205-206. 
[2] Lee, E.J., Kim, J.S., Kim, H.P., et al. (2010) Phenolic Constituents from the Flowers Bud of Lonicera Japonica and Their 5-li-Poxygenase Inhibitory Activities. Food Chemistry, 120, 134-139. http://dx.doi.org/10.1016/j.foodchem.2009.09.088

[3] Bassoli, B.K., Cassolla, P., Borba-Murad, G.R., et al. (2008) Chlorogenic Acid Reduces the Plasma Glucose Peak in the Oral Glucose Tolerance Test. Effects on Hepatic Glucose Release and Glycaemia. Cell Biochemistry and Function, 26, 320-328. http://dx.doi.org/10.1002/cbf.1444

[4] Macrcos, A.B., Ricardo, E.S., Eliane, P.O., et al. (2008) Response Surface Methodology (RSM) as a Tool for Optimization in Analytical Chemistry. Talanta, 76, 965-977. http://dx.doi.org/10.1016/j.talanta.2008.05.019

[5] Wu, J.H, Wang, L., Gao, F., et al. (2011) Study on Enzyme-Assisted Extraction of Lentinan. Food and Fermentation Industries, 37, 201-205 (in Chinese).

[6] Lee, S., Bae, H., Kim, N., et al. (2008) Optimization of Growth Condition of Lentinus Edodes Mycelium on Corn Processing Waste Using Response Surface Analysis. Journal of Bioscience and Bioengineering, 105, 161-163.

[7] Huang, L., Tang, J.L., Huang, J., et al. (2012). Research Progress in Application and Chlorogenic Acid Extraction. University Laboratory Study and Work, 113, 114-117 (in Chinese).

[8] Abraham, S.K. (1993) Protective Effects of Chlorogenic Acid, Curcuin in and a $\alpha$-Carotene Against $\gamma$-Radiation Induced in Vitro Chromosomal Damage. Mutation Research, 303, 10-11.

[9] Yong, L., Shoulian, W. and Miaochuan, L. (2013) Optimization of Ultrasonic Extraction of Phenolic Compounds from Euryale Ferox Seed Shells Using Response Surface Methodology. Industrial Crops and Products, 49, 837-848. http://dx.doi.org/10.1016/j.indcrop.2013.07.023

[10] Pinho, C., Melo, A., Mansilha, C. and Ferreira, I.M.P.L.V.O. (2011) Optimization of Conditions for Anthocyanin Hydrolysis from Red Wine Using Response Surface Methodology (RSM). Journal of Agricultural and Food Chemistry, 59, 50-55. http://dx.doi.org/10.1021/jf103839j

[11] Chen, W., Wang, W.P., Zhang, H.S. and Huang, Q. (2012) Optimization of Ultrasonic-Assisted Extraction of WaterSoluble Polysaccharides from Boletus edulis Mycelia Using Response Surface Methodology. Carbohydrate Polymers, 87, 614-619. http://dx.doi.org/10.1016/j.carbpol.2011.08.029

[12] Carrera, C., Ruiz-Rodríguez, A., Palma, M. and Barroso, C.G. (2012) Ultrasound Assisted Extraction of Phenolic Compounds from Grapes. Analytica Chimica Acta, 732, 100-104. http://dx.doi.org/10.1016/j.aca.2011.11.032

[13] Li, Q. and Fu, C. (2005) Application of Response Surface Methodology for Extraction Optimization of Germinant Pumpkin Seeds Protein. Food Chemistry, 92, 701-706. http://dx.doi.org/10.1016/j.foodchem.2004.08.042

[14] Sheng, Z.L., Wan, P.F., Dong, C.L. and Li, Y.H. (2013) Optimization of Total Chlorogenic Content Extracted from Flos Populi Using Response Surface Methodology. Industrial Crops and Products, 43, 778-786. http://dx.doi.org/10.1016/j.indcrop.2012.08.020

[15] Ferreira, S.L., Bruns, R.E., Ferreira, H.S., Matosa, G.D., Davida, J.M., Brandão, G.C., et al. (2007) Box-Behnken Design: An Alternative for the Optimization of Analytical Methods. Analytical chemistry Acta, 597, 179-186. http://dx.doi.org/10.1016/j.aca.2007.07.011

[16] Spigno, G. and De Faveri, D.M. (2009) Microwave-Assisted Extraction of Tea Phenols: A Phenomenological Study. Journal of Food Engineering, 93, 210-217. http://dx.doi.org/10.1016/j.jfoodeng.2009.01.006

[17] Iwanhas, H., Negoro, Y., Ikeda, A., Morishita, H. and Kido, R. (1986) Inhibition by Chlorogenic Acid of HaematinCatalysed Retinoic Acid 5, 6-Epoxidation. The Biochemical Journal, 239, 641-646.

[18] Zhang, L., Liu, J., Zhang, P., Yan, S., He, X. and Chen, F. (2011) Ionic Liquid-Based Ultrasound-Assisted Extraction of Chlorogenic Acid from Lonicera japonica Thunb. Chromatographia, 73, 129-133. http://dx.doi.org/10.1007/s10337-010-1828-y

[19] Merabet, S., Robert, D., Weber, J.V., Bouhelassa, M. and Benkhanouche, S. (2009) Photocatalytic Degradation of Indole in $\mathrm{UV} / \mathrm{TiO}_{2}$ : Optimization and Modeling Using the Response Surface Methodology (RSM). Environmental Chemistry Letters, 7, 45-49. http://dx.doi.org/10.1007/s10311-008-0137-2

[20] Zhu, C. and Liu, X. (2013) Optimization of Extraction Process of Crude Polysaccharides from Pomegranate Peel by Response Surface Methodology. Carbohydrate Polymers, 92, 1197-1202. http://dx.doi.org/10.1016/j.carbpol.2012.10.073

[21] Song, D., Liang, Y. and Yang, G. (2010) Optimization on the Ultrasonic Treatment Extracting Process for Chlorogenic Acid from Lonicera japonica Thumb by Orthogonal Design. Journal of Animal and Veterinary Medicine, 2010, 37-40 (In Chinese).

[22] Yuan, F. (2012) Orthogonal Test Design for Optimization of Ultrasonic Extraction Process of Chlorogenic Acid from Honeysuckle. Chinese Journal of Chinese Guide, 2012, 913-916 (In Chinese). 